\title{
Redefinindo as práticas de Saúde a partir de experiências de Educação Popular nos serviços de saúde
}

\section{debates}

\author{
Redefining healthcare practices based on the \\ experiences of people education at healthcare services
}

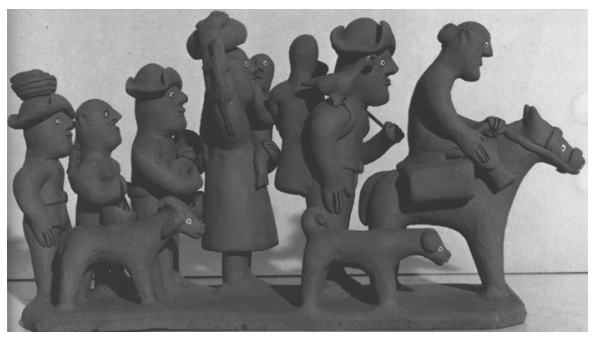

Eymard Mourão Vasconcelos ${ }^{1}$

Desde a década de setenta, profissionais de saúde insatisfeitos com as práticas mercantilizadas e rotinizadas dos serviços oficiais e desejosos de uma atuação mais significativa para as classes populares vêm se dirigindo às periferias dos grandes centros urbanos e regiões rurais em busca de formas alternativas de atuação. Inicialmente ligaram-se às experiências informais de trabalho comunitário, principalmente junto à Igreja Católica.

Posteriormente, a multiplicação de Serviços de Atenção Primária à Saúde ocorrida no Brasil, a partir do final dos anos setenta, colaborou na criação de condições institucionais para fixar esses profissionais nos locais de moradia das classes populares.

É interessante como este movimento de profissionais de saúde vem se mantendo por tantos anos. Convivendo com a dinâmica do processo de adoecimento e de cura no meio popular, interagindo com os movimentos sociais locais e entrando em contato com a militância de outros grupos intelectuais, muitos passam a reorientar suas práticas buscando enfrentar de uma forma mais global os problemas de saúde encontrados. Em alguns desses serviços, em que a população organizada e os profissionais de saúde identificados com os seus interesses conseguem conquistar um maior controle do seu funcionamento, surgem algumas experiências pioneiras que avançam bastante na superação do caráter mercantil, biologicista $e$

${ }^{1}$ Professor do Departamento de Promoção da Saúde, Universidade Federal da Paraíba. <eymard@altavista.net> 
alienador da prática médica dominante. São experiências esparsas e pontuais, sempre ameaçadas de submersão diante das constantes oposições: a carência de recursos das políticas sociais, a repressão política $e$ as exigências do produtivismo numérico do sistema de saúde. Em um número maior de serviços, profissionais comprometidos politicamente com a população não conseguem conquistar a hegemonia do seu funcionamento, mas resistem implementando pequenas práticas alternativas e marginais, nas quais a relação educativa com a população é priorizada.

Nesses serviços, a participação e o controle dos grupos populares não são apenas esperados e franqueados, mas investe-se intensamente nos seus aprofundamentos. Busca-se constantemente a articulação com os sindicatos de trabalhadores, grupos pastorais, associações de moradores, grupos de jovens, conselhos paroquiais, grupos de mulheres etc. Quando estas entidades populares são pouco expressivas, estimula-se o seu fortalecimento ou a criação de novos grupos. Também investe-se na estruturação de comitês locais de saúde.

A relação com a população, de forma alguma, se restringe aos grupos organizados. Há uma grande valorização das trocas interpessoais que acontecem tanto nos contatos formais (consultas individuais, reuniões educativas e visitas domiciliares) como também nos contatos informais e na participação em eventos sociais locais. Na dinâmica desses serviços de saúde, a palavra diálogo é um conceito fundamental. Um diálogo no qual esforça-se para compreender e explicitar o saber do interlocutor popular. Em várias experiências, os profissionais radicalizam esta busca de aproximação do meio popular indo, inclusive, morar próximo a esses grupos.

Nesses serviços é nítida a quebra do poder centralizador dos médicos. Predomina um discurso igualitarista que coloca em pé de igualdade todos os profissionais, inclusive os agentes comunitários de saúde. Mesmo que o discurso não corresponda totalmente à prática diária, estrutura-se uma série de mecanismos (assembléia de funcionários, reuniões de equipe, encontros de avaliação) no qual cada profissional conta, pelo menos, com a possibilidade formal de participar na definição das prioridades e estratégias e no enfrentamento dos problemas detectados. Tudo é problema de todos!

Ao mesmo tempo, a maior inserção desses Serviços de Atenção Primária à Saúde no meio popular, devido a sua localização e ligação com os movimentos sociais, cria condições para que a globalidade dos problemas de saúde se manifeste, desafiando as limitações e competências individuais dos vários profissionais e especialistas. Assim, a interdisciplinaridade passa a ser cobrada não só pela vontade de alguns deles, mas também a partir das demandas da população. O intercâmbio entre os vários profissionais passa a existir não apenas na definição de estratégias globais do serviço, mas também para enfrentar os pequenos problemas de saúde. A partir da articulação com diferentes formações, estrutura-se, aos poucos, uma prática de saúde alargada (não simplificada), em que as várias dimensões da doença passam a ser enfrentadas. Com a pressão dos grupos populares locais, as dimensões coletivas dos problemas de saúde incorporam-se ao cotidiano dos serviços.

\section{Interface - Comunic, Saúde, Educ 8}

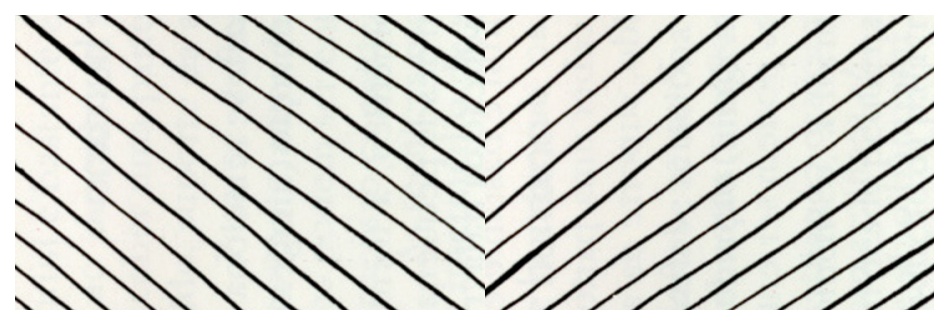


Nesse contexto, preocupa-se não apenas em multiplicar os atendimentos e expandir a população por eles coberta, mas em redefinir o próprio atendimento. É comum afirmar, com graus variáveis de clareza, que a atenção médica tradicional não é injusta apenas porque segrega os trabalhadores, mas também porque a sua racionalidade interna reforça $e$ recria, no nível das suas microrelações, as estruturas de dominação da sociedade. O biologicismo, o autoritarismo do doutor, o desprezo ao saber e à iniciativa do doente e familiares, a imposição de soluções técnicas para problemas sociais globais e a propaganda embutida dos grupos políticos dominantes, são exemplos de alguns dos mecanismos entranhados na assistência à saúde oficial que se procura superar. Desta forma, os serviços inovam até mesmo em relação a amplos setores dos profissionais de saúde considerados progressistas (a chamada "esquerda médica" nucleada em torno do antigo Partido Comunista Brasileiro) que, preocupados com a expansão do direito a assistência à saúde junto a população, não questionam o tipo de assistência que está sendo expandida.

Essas experiências alternativas estruturaram-se a partir da década de setenta em bairros periféricos, pequenas cidades do interior e povoados rurais, integrados a projetos mais amplos nos quais a metodologia da Educação Popular era hegemônica. Pelo contato com várias dessas experiências, com inúmeros profissionais nelas inseridos, percebo que o método da Educação Popular foi um elemento estruturante fundamental. As experiências se constituíram no mesmo ambiente sócio-econômico e cultural em que a Educação Popular terminava de se delinear como corpo teórico: as comunidades eclesiais de base, o ressurgimento dos movimentos sociais em luta contra a ditadura militar e suas políticas econômicas e sociais na década de setenta. Naquele contexto, a Educação Popular era a teoria hegemônica que orientava o modo de participação dos agentes eruditos (professores, padres, cientistas sociais, profissionais de saúde etc.) engajados no trabalho político e pedagógico.

Assim, no setor Saúde, a Educação Popular passou a se constituir, em vários serviços, não como uma atividade a mais entre tantas outras, mas como um instrumento de reorientação da globalidade de suas práticas, na medida em que dinamiza, desobstrui e fortalece a relação com a população $e$ seus movimentos organizados.

A Educação em Saúde é o campo de prática e conhecimento do setor Saúde que tem se ocupado mais diretamente com a criação de vínculos entre a ação médica e o pensar e fazer cotidiano da população. Diferentes concepções e práticas têm marcado a história da Educação em Saúde no Brasil. Mas, até a década de setenta, foi basicamente uma iniciativa das elites políticas e econômicas e, portanto, subordinada aos seus interesses. Voltavase para a imposição de normas e comportamentos por elas considerados adequados, num tipo de educação que poderia ser chamada de "toca boiada", em que os técnicos e a elite vão tentando conduzir a população para os caminhos que consideram corretos, usando, para isto, tanto o berrante (a palavra) como o ferrão (o medo e a ameaça). 
A participação de profissionais de saúde nas experiências de Educação Popular, a partir dos anos setenta, trouxe para o setor Saúde uma cultura de relação com as classes populares que representou uma ruptura com a tradição autoritária e normatizadora da Educação em Saúde.

No âmbito internacional, o Brasil teve um papel pioneiro na constituição do método da Educação Popular, o que explica, em parte, a sua importância, aqui, na redefinição de práticas sociais dos mais variados campos do saber. Ela começa a se estruturar como corpo teórico e prática social no final da década de cincoenta, quando intelectuais e educadores ligados à Igreja Católica e influenciados pelo humanismo personalista que florescia na Europa no pós-guerra, voltam-se para as questões populares. Na verdade, o movimento operário brasileiro, desde o início do século, enfatizara muito a dimensão cultural e da consciência no processo de luta. Marcado pelas correntes anarquistas trazidas pelos imigrantes europeus, ele via a exploração do trabalhador também pela dimensão moral e cultural. Assim, os sindicatos e grupos operários, no início do século, preocupavam-se muito em promover discussões sobre questões culturais, organizar bibliotecas, organizar passeios nos fins de semana e criar escolas noturnas. Mas a partir do governo de Getúlio Vargas, o Estado passa a assumir a iniciativa da cobertura (simplificada) dos direitos sociais, esvaziando a iniciativa operária. Desta forma, o movimento da Educação Popular representa uma retomada e uma elaboração pelos intelectuais $e$ agentes educativos de uma prática esparsa e não sistematizada do movimento operário do início do século.

Educação Popular não é o mesmo que "educação informal". Há muitas propostas educativas que se dão fora da escola, mas que utilizam métodos verticais de relação educador-educando. Segundo Brandão (1982), a Educação Popular não visa criar sujeitos subalternos educados: sujeitos limpos, polidos, alfabetizados, bebendo água fervida, comendo farinha de soja e cagando em fossas sépticas. Visa participar do esforço que já fazem hoje as categorias de sujeitos subalternos - do índio ao operário do $A B C$ paulista - para a organização do trabalho político que, passo a passo, abra caminho para a conquista de sua liberdade e de seus direitos. A Educação Popular é um modo de participação de agentes eruditos (professores, padres, cientistas sociais, profissionais de saúde e outros) neste trabalho político. Ela busca trabalhar pedagogicamente o homem e os grupos envolvidos no processo de participação popular, fomentando formas coletivas de aprendizado e investigação de modo a promover o crescimento da capacidade de análise crítica sobre a realidade e o aperfeiçoamento das estratégias de luta e enfrentamento.

Um elemento fundamental do seu método é o fato de tomar como ponto de partida do processo pedagógico o saber anterior das classes populares. No trabalho, na vida social e na luta pela sobrevivência e pela transformação da realidade, as pessoas vão adquirindo um entendimento sobre a sua inserção na sociedade e na natureza. Este conhecimento fragmentado e pouco elaborado é a matéria prima da Educação Popular. A valorização do saber popular permite que o educando se sinta "em casa" e mantenha a sua iniciativa. Neste sentido, não se reproduz a passividade usual dos processos 
pedagógicos tradicionais. Na Educação Popular não basta que o conteúdo discutido seja revolucionário, se o processo de discussão se mantém vertical.

Passados quarenta anos do início deste movimento no Brasil, muita coisa mudou. As práticas de Educação Popular em Saúde já não se restringem ao modelo dominante na década de setenta: um técnico inserido em uma pequena comunidade periférica, identificando lideranças e problemas mobilizadores, criando espaços de debate, apoiando as lutas emergentes $e$ trazendo subsídios teóricos para alargar as discussões locais. Com o processo de democratização da sociedade brasileira, houve espaço para que a participação popular pudesse também ocorrer nas grandes instituições. Muitos técnicos formados nos espaços informais dos movimentos sociais passaram a ocupar cargos importantes nos órgãos implementadores das políticas de saúde procurando aplicar, neste novo espaço, a metodologia da Educação Popular. Apesar de uma certa crise inicial da $\left\{\begin{array}{l}3 \\ 1\end{array}\right.$ pretensão de transposição direta e sem adaptações da metodologia de ação nos espaços informais para as instituições, novas experiências floresceram. A Rede de Educação Popular e Saúde que, desde 1991, articula profissionais de saúde e lideranças populares envolvidas nestas experiências, vem se expandindo e consolidando a trajetória de atuação nos novos serviços de saúde a partir do instrumental da Educação Popular.

Pode-se afirmar que uma grande parte das experiências de Educação Popular em Saúde estão hoje voltadas para a superação do fosso cultural existente entre os serviços de saúde, as organizações não governamentais, o saber médico e mesmo as entidades representativas dos movimentos sociais de um lado e, de outro lado, a dinâmica de adoecimento $e$ de cura do mundo popular. Isto é feito a partir de uma perspectiva de compromisso com os interesses políticos das classes populares, mas reconhecendo, cada vez mais, a sua diversidade e heterogeneidade. Priorizase a relação com os movimentos sociais por serem expressões mais elaboradas desses interesses. Atuando a partir de problemas de saúde específicos ou de questões ligadas ao funcionamento global dos serviços, busca-se entender, sistematizar e difundir a lógica, o conhecimento e os princípios que regem a subjetividade dos vários atores envolvidos, de forma a superar incompreensões e mal entendidos ou tornar conscientes $e$ explícitos os conflitos de interesse. Dedica-se à ampliação dos canais de interação cultural e negociações (cartilhas, jornais, assembléias, reuniões, cursos, visitas etc.) entre os diversos grupos populares e os diversos tipos de profissionais e instituições.

A Educação Popular não é o único projeto pedagógico a valorizar a diversidade e heterogeneidade dos grupos sociais, a intercomunicação entre diferentes atores, o compromisso com as classes subalternas, as iniciativas dos educandos e o diálogo entre o saber popular e o saber científico. Mas para o setor Saúde brasileiro, a participação histórica no movimento da Educação Popular foi marcante na criação de um movimento de profissionais que busca romper com a tradição autoritária e normatizadora da relação 
DEBATES

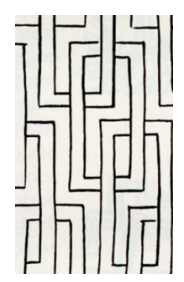

entre os serviços de saúde e a população. Apesar de uma certa crise do conceito da Educação Popular nos novos tempos, é ele que vem servindo para identificar e instrumentalizar a diversidade de práticas emergentes. Nessas experiências, os vários aspectos metodológicos valorizados articulam-se de um modo peculiar, diferenciando-se do que ocorre em outros continentes. Há um elemento inovador e pioneiro nas experiências brasileiras e latino-americanas de Educação em Saúde que vêm sendo reconhecido internacionalmente.

Para muitos serviços de saúde, a Educação Popular tem significado um instrumento fundamental na construção histórica de uma medicina integral, na medida em que se dedica à ampliação da inter-relação entre as diversas profissões, especialidades, serviços, doentes, familiares, vizinhos e organizações sociais locais envolvidos num problema específico de saúde, fortalecendo e reorientando suas práticas, saberes e lutas. Esta redefinição da prática médica se dá, não a partir de uma nova tecnologia ou um novo sistema de conhecimento, como as chamadas medicinas alternativas pretendem ser, mas pela articulação de múltiplas, diferentes e até contraditórias iniciativas presentes em cada problema de saúde, em um processo que valoriza principalmente os saberes e práticas dos sujeitos usualmente desconsiderados devido a sua origem popular.

No atual contexto de fragmentação da vida social, a recomposição de uma abordagem mais globalizante da saúde não pode caber apenas às iniciativas ampliadas das instituições médicas. Cabe principalmente ao crescimento da capacidade de doentes, famílias, movimentos sociais e outros setores da sociedade civil em articularem, usufruírem e reorientarem os diversos serviços e saberes disponíveis. Esta perspectiva se diferencia do imaginário de grande parte do movimento sanitário brasileiro, ainda acreditando $e$ empenhando-se na possibilidade de construção de um sistema estatal único de saúde capaz de, planejadamente, penetrar e ordenar as diversas instâncias da vida social implicadas no processo de adoecimento e de cura. (Vasconcelos, 1997).

Referências bibliográficas

BRANDÃO, C. R. Lutar com a palavra: escritos sobre o trabalho do educador. Rio de Janeiro: Graal, 1982.

VASCONCELOS, E. M. Educação Popular nos serviços de saúde. 3 ed. São Paulo: Hucitec, 1997.

PALAVRAS-CHAVE: Educação Popular; práticas de Saúde; Educação em Saúde.

KEY WORDS: People Education; Healthcare practice; Healthcare Education.

PALABRAS-CLAVE: Educación Popular; prácticas de la Salud; Educación en Salud.

Recebido para publicação em: 20/10/00. Aprovado para publicação em: 05/11/00.

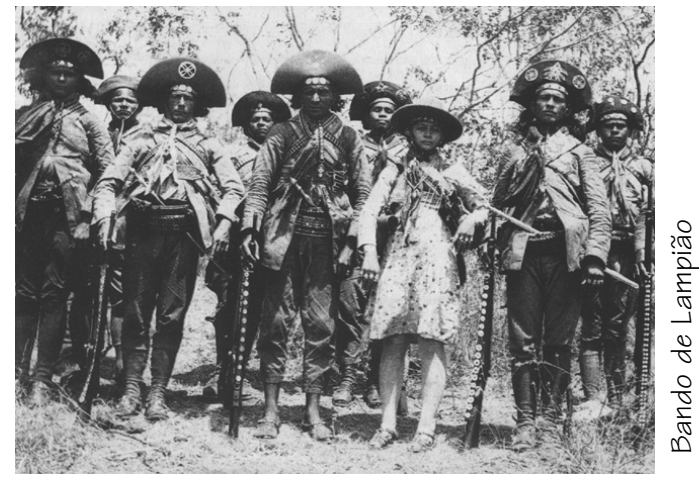

